\title{
Cave canem: urine is not urine in corona times
}

\author{
Kunz Yannic ${ }^{\ddagger}, 1$, Horninger Wolfgang ${ }^{1}$ \& Pinggera Germar-Michael*, $\neq, 1$ (iD \\ ${ }^{1}$ Department of Urology, Medical University Innsbruck, Anichstrasse 35, A-6020, Innsbruck, Austria \\ *Author for correspondence: Tel.: +43 512504 24811; Germar.pinggera@tirol-kliniken.at \\ ${ }^{\ddagger}$ Authors contributed equally
}

First draft submitted: 6 July 2020; Accepted for publication: 31 July 2020; Published online: 27 November 2020

KEYWORDS coronaviridae $\bullet$ COVID • detection rate $\bullet$ infection $\bullet$ review $\bullet$ SAR-CoV-2 $\bullet$ urine

Dear Editor,

We read and appreciated the article 'Implications of COVID-19 on urological laparoscopic surgery' by Condon et al. published on 9 June 2020 with great interest [1]. We wish to thank the authors for offering guidance in these difficult times of a SARS-CoV-2 pandemic. A comprehensive overview on surgical risk of infection with SARS-CoV-2 is given, as well as information on the reliability of current testing. While providing interesting information, especially on laparoscopic surgery, but also endourology, it is stated that SARS-CoV-2 has not been isolated in the urine thus far. Although positive respiratory, blood and feces specimens are correctly described in the article, the findings of detectable SARS-CoV-2 in the urine is still on debate and ongoing studies are providing further evidence. Therefore, we wish to emphasize that current evidence suggests a possible infectious hazard within the urine.

Since the outbreak of the severe acute respiratory syndrome coronavirus due to an enveloped, positive-sense, single-stranded RNA virus (SARS-CoV-1) in Asia in 2003, two important findings have been shown. First, it was demonstrated that SARS-CoV-1 enters different human cells by binding mainly to (ACE2) [2]. Second, in several investigations, the presence of this coronavirus could be detected not only in the epithelial cells within the lungs [3] and the feces but also in the urine. Chan et al. investigated the detection of SARS-CoV in 386 patients with serologically confirmed SARS-CoV infection, which was not detectable in feces or urine specimens until days 5 and 7 of the illness, respectively [4]. Interestingly, the specific virus detection increased in the following measurements and was peaking at approximately day 11 of the illness. Finally, they discovered that viral RNA gradually decreased from day 16 onward but was still detectable until 30 days of illness (up to day 7, $0 \% \mathrm{CoV}+$; days 7 and 8 under $10 \% \mathrm{CoV}+$; days 11 and $12,>40$ to $<50 \% \mathrm{CoV}+$; after day 30, approximately $5 \% \mathrm{CoV}+$ ) [4]. In the study from Peiris et al., the detection rate for SARS-CoV in urine specimens by real-time (RT)-PCR was positive in 31 out of 74 investigated cases (41.9\%) on day 14 [5]. Similar results were published by the SARS Study Group with around $30 \%$ positive urine specimens collected on days 10-15 after the onset of symptoms in 111 patients, with a pretty high viral load by quantitative RT-PCR (RT-qPCR) of $4.4 \log 10$ copies/ml compared with $2.7 \log 10$ copies $/ \mathrm{ml}$ in the positive serum, respectively [6]. Nevertheless, viral urine cultures were positive for SARS-CoV in only one out of 20 performed measurements. Again, the SARS Study Group showed a detection rate of 26/177 (14.7\%) in urine specimens of 177 SARS antibody-positive patients [6].

However, the current situation for SARS-CoV-2-related infectious disease is slightly different and not fully understood for now. The size of the actual SARS-CoV-2 genome is $29.9 \mathrm{~kb}$, whereas the genomes of SARS-CoV and MERS-CoV are $27.9 \mathrm{~kb}$ and $30.1 \mathrm{~kb}$, respectively and all of them are considered within the group of the betacoronavirus (the genome sequence of SARS-CoV-2 was first released on Virological.org) [7].

Meanwhile, it is clearly demonstrated that even SARS-CoV-2, which is genetically similar to the coronavirus strain SARS-CoV-1 virus, has likewise his primary human receptor by ACE2 [8,9], which was first identified in 2003 [10]. In the biolayer interferometry study, it was shown recently that SARS-CoV-2 has a similar affinity to ACE2, like SARS-CoV-1 [11]. Even though there is no doubt that the lung is the most severely injured organ by SARS-CoV-2 infection, SARS-CoV-2 can harm many other organs, such as the heart, liver, kidney, brain and intestines. This 
is always in conjunction with the widespread presence of the corresponding docking side in these organs [12-14]. Indeed, ACE2 has been identified as the SARS-CoV-2 receptor widely present in the human kidney and thus these findings of organ tropism are of high importance in understanding virus elimination, disease progression and fatality rate $[15,16]$. The ACE2 expressions as membrane-bound proteins are found mainly in the brush border of the proximal tubular units and, to a lesser extent, the podocytes, but not in the glomerular, endothelial and mesangial cells. Moreover, the net surface expression of this ACE2 receptor has been shown to be altered in several clinical conditions, such as diabetes, arterial hypertension and heart disease [17]. Once the kidneys' morphological structures are damaged after SARS-CoV-2 infection, this might lead to acute kidney failure (AKI) [18,19]. By Kaplan-Meier analysis, it was demonstrated that renal failure had a greater risk for in-hospital mortality, and finally, Cox regression models confirmed AKI as an independent risk factor for predicting in-hospital patients' mortality [10]. Therefore, it is conceivable that particles or complete SARS-CoV-2 virus might be detectable in the urine. It is possible that urinary excretion is dependent on the infection cycle or severity of tissue damage.

Thus, to assess and figure out any renal damage by SARS-CoV-2, a systematic, prospective investigation with an autopsy registry was initiated to facilitate COVID-19 research [20].

As stated in our recent review [21], three work groups isolated viral nucleic acid in the urine in various patients. This seems to be especially delicate since urine specimens remain positive even after a negative pharyngeal swab [2224]. Still, more recent studies underline these findings. The Chinese work group of Ling et al. recently published a positive urine detection rate of 6.9\% (4/58) [22]. This is supported by Zhang et al., who observed a detection rate of $8.7 \%(2 / 23)$ [25] in one collective and 1.5\% (1/67) in another [26]. Wang et al. investigated 48 patients with confirmed COVID-19 and proofed SARS-CoV-2 RNA in 6.25\% (3/48) of cases [23]. Similarly, Peng et al. showed SARS-CoV-2 in one patient from a small positively tested collective, $11.1 \%(1 / 9)$ [24]. More recently, the Korean group by Kim et al. tested two patients positive in the urine in a bigger collective, $0.8 \%(2 / 247)$ [27] and by Sun et al. in a well-characterized patient case [28].

According to these six studies, roughly $3 \%$ of the tested patients showed positive results in the urine $(13 / 452)$, posing a possible hazard for their caretakers. Therefore, disease transmission risk during urologic interventions by urine should not be completely neglected; especially urologists should not be careless in this field. Nevertheless, the transmission pathways of SARS-CoV-2 are not yet completely understood, the viral load might be only of transient character and the actual infection rate by SARS-CoV-2 via positive urine specimens remains to be investigated. In addition, the study designs are very different. Especially sample time differs vastly between the protocols, possibly explaining the different outcomes. Considering that SARS-CoV-2 could sometimes not be detected within the same patient at different measurements, there is implication for potentially increased unknown numbers.

On the contrary, we have to appreciate that there are several other studies not in line with the preceding findings. The following authors did not find any positive urine samples with any evidence of SARS-CoV-2: Kujawski et al. $(\mathrm{n}=0 / 10)$ [29], Wolfel et al. (urine: $\mathrm{n}=0 / 27$ [0\%] CoV+ samples) [30], Cai et al. (urine: $\mathrm{n}=0 / 6$ [0\%] CoV+ [31], Chan et al. (urine: $\mathrm{n}=0 / 3$ [0\%] patients CoV+ [32], Lo et al. (urine: $\mathrm{n}=0 / 49[0 \%] \mathrm{CoV}+[33]$ and Lescure et al. (urine: $\mathrm{n}=0 / 5[0 \%] \mathrm{CoV}+$ patients [34].)

Summarizing the mentioned data, it appears that these inherent study conflicts are explained by low sample analysis, unclear methodological quality of the studies, temperature and needed time of sample assessment, as well as time of sample investigation after disease onset.

Irrespective of these diverging results on urine contamination, it should be at least recognized that several study groups found SARS-CoV-2 viral load in the urine. Furthermore, SARS-CoV-2 was even detected in wastewater by RT-PCR [35-37]. In addition, we wish to present a Chinese study with $15 \%$ positive findings of SARS-CoV-2 in semen analysis as well, as this might concern urologists in their daily routine [38,39].

The safety of healthcare workers should be the primary concern and guideline to the treatment of COVID-19 patients. This is even more relevant in tandem with the newly published data on COVID-19 cases among healthcare workers [40]. We would like to emphasize that we strongly agree with the original authors in this instance.

Therefore, in accordance with the positive findings of SARS-CoV-2 in the urine mentioned previously, we recommend, in unison with the European Association of Urology guidelines on COVID-19 [41], special precautions even in endourology. The reassurance given by the original authors (Condon et al. [1]) at least for endourologists cannot be approved by us. Therefore, personal protective equipment with FFP-2 masks and face shields should be utilized. Furthermore, closed suction devices for urine drainage seem reasonable. These recommendations are also in accordance with the newly published guidelines by strengthening all measures for protection of occupational health, safety and security of health workers by the WHO (WHO/2019-nCoV/HCF operations/2020.1) or others. 
However, especially oncologic endourologic interventions should not be postponed indefinitely in SARS-CoV-2 patients, when in fact net virus transmission by infected urine has not been described to date.

\section{Financial \& competing interests disclosure}

The authors have no relevant affiliations or financial involvement with any organization or entity with a financial interest in or financial conflict with the subject matter or materials discussed in the manuscript. This includes employment, consultancies, honoraria, stock ownership or options, expert testimony, grants or patents received or pending, or royalties.

No writing assistance was utilized in the production of this manuscript.

\section{References}

1 Condon B, Whish-Wilson T, Davis NF, Lawrentschuk N. Implications of COVID-19 on urological laparoscopic surgery. Future Oncol. 16(26), 1941-1945 (2020).

2 Ge XY, Li JL, Yang XL et al. Isolation and characterization of a bat SARS-like coronavirus that uses the ACE2 receptor. Nature 503(7477), 535-538 (2013).

3 Fehr AR, Perlman S. Coronaviruses: an overview of their replication and pathogenesis. Methods Mol. Bio. 1282, 1-23 (2015).

4 Chan KH, Poon LL, Cheng VC et al. Detection of SARS coronavirus in patients with suspected SARS. Emerg. Infect. Dis. 10(2), 294-299 (2004).

5 Peiris JS, Chu CM, Cheng VC et al. Clinical progression and viral load in a community outbreak of coronavirus-associated SARS pneumonia: a prospective study. Lancet 361(9371), 1767-1772 (2003).

6 SARS Study Group. Quantitative detection of SARS-CoV RNA in excreta and oropharyngeal washing fluid from convalescence patients with severe acute respiratory syndrome. Zhongguo Yi Xue Ke Xue Yuan Xue Bao 3(26), 251-254 (2004).

7 Wu F, Zhao S, Yu B et al. A new coronavirus associated with human respiratory disease in China. Nature 579(7798), 265-269 (2020).

8 Zhou P, Yang XL, Wang XG et al. A pneumonia outbreak associated with a new coronavirus of probable bat origin. Nature 579(7798), $270-273$ (2020).

9 Letko M, Marzi A, Munster V. Functional assessment of cell entry and receptor usage for SARS-CoV-2 and other lineage B betacoronaviruses. Nat. Microbiol. 5(4), 562-569 (2020).

$10 \mathrm{Li}$ W, Moore MJ, Vasilieva N et al. Angiotensin-converting enzyme 2 is a functional receptor for the SARS coronavirus. Nature 426(6965), 450-454 (2003).

11 Walls AC, Park YJ, Tortorici MA, Wall A, McGuire AT, Veesler D. Structure, function, and antigenicity of the SARS-CoV-2 spike glycoprotein. Cell 181(2), 281-292.e6 (2020).

12 Gheblawi M, Wang K, Viveiros A et al. Angiotensin converting enzyme 2: SARS-CoV-2 receptor and regulator of the renin-angiotensin system: celebrating the 20th anniversary of the discovery of ACE2. Circ. Res. 126(10), 1456-1474 (2020).

13 Tang D, Comish P, Kang R. The hallmarks of COVID-19 disease. PLoS Pathog. 16(5), e1008536 (2020).

14 Yan R, Zhang Y. Structural basis for the recognition of SARS-CoV-2 by full-length human ACE2. Science 367(6485), 1444-1448 (2020).

15 Varga Z, Flammer AJ, Steiger P et al. Endothelial cell infection and endotheliitis in COVID-19. Lancet 395(10234), 1417-1418 (2020).

16 Su H, Yang M, Wan C et al. Renal histopathological analysis of 26 postmortem findings of patients with COVID-19 in China. Kidney Int. 98(1), 219-227 (2020).

17 Ghafouri-Fard S, Noroozi R, Omrani MD et al. Angiotensin converting enzyme: a review on expression profile and its association with human disorders with special focus on SARS-CoV-2 infection. Vascul. Pharmacol. 130, 106680 (2020).

18 Perico L, Benigni A, Remuzzi G. Should COVID-19 concern nephrologists? Why and to what extent? The emerging impasse of angiotensin blockade. Nephron 144(5), 213-221 (2020).

19 Valizadeh R, Baradaran A, Mirzazadeh A, Bhaskar LVKS. Coronavirus-nephropathy; renal involvement in COVID-19. J. Renal Inj. Prev. 9(2), e18 (2020).

20 von Stillfried S, Bulow RD, Rohrig R et al. Autopsy registry can facilitate COVID-19 research. EMBO Mol. Med. e12885 (2020).

21 Kunz Y, Horninger W, Pinggera GM. Are urologists in trouble by SARS-CoV-2? Reflexions and recommendations for specific interventions. BJU Int. doi:10.1111/bju.15141 (2020) (Epub ahead of print).

22 Ling Y, Xu SB, Lin YX et al. Persistence and clearance of viral RNA in 2019 novel coronavirus disease rehabilitation patients. Chin. Med. J. (Engl.). 133(9), 1039-1043 (2020).

23 Wang $\mathrm{L}, \mathrm{Li}$ X, Chen $\mathrm{H}$ et al. Coronavirus disease 19 infection does not result in acute kidney injury: an analysis of 116 hospitalized patients from Wuhan, China. Am. J. Nephrol. 51(5), 343-348 (2020).

24 Peng L, Liu J, Xu W et al. 2019 novel coronavirus can be detected in urine, blood, anal swabs and oropharyngeal swabs samples. medRxiv. doi:10.1101/2020.02.21.20026179 (2020).

25 Zhang J, Wang S, Xue Y. Fecal specimen diagnosis 2019 novel coronavirus-infected pneumonia. J. Med. Virol. 92(6), 680-682 (2020). 
26 Zheng S, Fan J, Yu F et al. Viral load dynamics and disease severity in patients infected with SARS-CoV-2 in Zhejiang province, China, January-March 2020: retrospective cohort study. BMJ. 369, m1443 (2020).

27 Kim JM, Kim HM, Lee EJ et al. Detection and isolation of SARS-CoV-2 in serum, urine, and stool specimens of COVID-19 patients from the Republic of Korea. Osong Public Health Res. Perspect. 11(3), 112-117 (2020).

28 Sun J, Zhu A, Li H et al. Isolation of infectious SARS-CoV-2 from urine of a COVID-19 patient. Emerg. Microbes Infect. 9(1), 991-993 (2020).

29 Kujawski S, Wong K, Collins J et al. First 12 patients with coronavirus disease 2019 (COVID-19) in the United States. medRxiv doi:10.1101/2020.03.09.20032896 (2020).

30 Wolfel R, Corman VM, Guggemos W et al. Virological assessment of hospitalized patients with COVID-2019. Nature 581(7809), 465-469 (2020).

31 Cai J, Xu J, Lin D et al. A case series of children with 2019 novel coronavirus infection: clinical and epidemiological features. Clin. Infect. Dis. doi:10.1093/cid/ciaa198 (2020) (Epub online ahead of print).

32 Chan JF, Yuan S, Kok KH et al. A familial cluster of pneumonia associated with the 2019 novel coronavirus indicating person-to-person transmission: a study of a family cluster. Lancet 395(10223), 514-523 (2020).

33 Lo IL, Lio CF, Cheong HH et al. Evaluation of SARS-CoV-2 RNA shedding in clinical specimens and clinical characteristics of 10 patients with COVID-19 in Macau. Int. J. Biol. Sci. 16(10), 1698-1707 (2020).

34 Lescure FX, Bouadma L, Nguyen D et al. Clinical and virological data of the first cases of COVID-19 in Europe: a case series. Lancet Infect. Dis. 20(6), 697-706 (2020).

35 Bivins A, North D, Ahmad A et al. Wastewater-based epidemiology: global collaborative to maximize contributions in the fight against COVID-19. Environ. Sci. Technol. 54(13), 7754-7757 (2020).

36 Ahmed W, Angel N, Edson J et al. First confirmed detection of SARS-CoV-2 in untreated wastewater in Australia: a proof of concept for the wastewater surveillance of COVID-19 in the community. Sci. Total Environ. 728, 138764-138764 (2020).

37 La Rosa G, Iaconelli M, Mancini P et al. First detection of SARS-CoV-2 in untreated wastewaters in Italy. Sci. Total Environ. 736, $139652(2020)$.

38 Li D, Jin M, Bao P, Zhao W, Zhang S. Clinical characteristics and results of semen tests among men with coronavirus disease 2019. JAMA Network Open. 3(5), e208292-e208292 (2020).

39 Paoli D, Pallotti F, Colangelo S et al. Study of SARS-CoV-2 in semen and urine samples of a volunteer with positive naso-pharyngeal swab. J. Endocrinol. Invest. doi:10.1007/s40618-020-01261-1 (2020) (Epub ahead of print).

40 Contejean A, Leporrier J, Canoui E et al. Comparing dynamics and determinants of SARS-CoV-2 transmissions among health care workers of adult and pediatric settings in central Paris. Clin. Infect. Dis. doi:10.1093/cid/ciaa977 (2020) (Epub ahead of print).

41 EAU Guidelines Office Rapid Reaction Group. An organisation-wide collaborative effort to adapt the EAU guidelines recommendations to the COVID-19 era. https://uroweb.org/wp-content/uploads/EAU-Guidelines-Office-Rapid-Reaction-Group-An-organisation-wid e-collaborative-effort-to-adapt-the-EAU-guidelines-recommendations-to-the-COVID-19-era.pdf 